\title{
Omi, a recessive mutation on chromosome 10 , is a novel allele of Ostm1
}

\author{
Erika A. Bosman • Jeanne Estabel • \\ Ozama Ismail · Christine Podrini • \\ Jacqueline K. White $\cdot$ Karen P. Steel
}

Received: 28 May 2012/Accepted: 11 September 2012/Published online: 17 November 2012

(C) The Author(s) 2012. This article is published with open access at Springerlink.com

\begin{abstract}
Large-scale $N$-ethyl- $N$-nitrosourea (ENU) mutagenesis has provided many rodent models for human disease. Here we describe the initial characterization and mapping of a recessive mutation that leads to degeneration of the incisors, failure of molars to erupt, a grey coat colour, and mild osteopetrosis. We mapped the omi mutation to chromosome 10 between D10Mit214 and D10Mit194. The Ostm 1 gene is a likely candidate gene in this region and the grey-lethal allele, Ostm $1^{g l}$, and omi mutations fail to complement each other. We show that om/om mice have reduced levels of Ostm1 protein. To date we have not been able to identify the causative mutation. We propose that omi is a novel hypomorphic mutation affecting Ostml expression, potentially in a regulatory element.
\end{abstract}

\section{Introduction}

Large-scale $N$-ethyl- $N$-nitrosourea (ENU) mutagenesis has provided many rodent models for human disease, including several forms of deafness, Branchio-Oto-Renal syndrome, and CHARGE syndrome (Hrabe de Angelis et al. 2000; Smits et al. 2005; Bosman et al. 2005, 2009;

Electronic supplementary material The online version of this article (doi:10.1007/s00335-012-9438-7) contains supplementary material, which is available to authorized users.

E. A. Bosman · J. Estabel · O. Ismail · C. Podrini ·

J. K. White - K. P. Steel $(\bowtie)$

Wellcome Trust Sanger Institute, Wellcome Trust Genome

Campus, Hinxton, Cambridge CB10 1SA, UK

e-mail: kps@sanger.ac.uk

E. A. Bosman

e-mail: eabosman@yahoo.com
Calvert et al. 2011; Hilton et al. 2011). Due to the nature of production of these mutant mice, it is likely that additional mutations are present in the mouse lines studied because mutations are generated at random in the genome and are usually noticed only when they lead to a detectable phenotype. Some mutations may be without any obvious consequence, but other mutations may have additional phenotypes of varying degree that may go undetected because they are not screened for or they may appear in later generations if they are recessive. It has been estimated that an average of around 150 mutations occur in each $\mathrm{F} 1$ offspring from an ENU-mutagenized male (Hrabe de Angelis et al. 2000). Many of these additional mutations will be lost by dilution in successive generations through crossing to the wild-type background (Hilton et al. 2011) or by selection against the mutant phenotype; however, some will remain.

We report here a new recessive phenotype that was found in a line selected for a completely different phenotype originating from an ENU mutagenesis screen. The phenotype was initially detected due to high lethality just after weaning in some matings within this mouse line. Here we describe the initial characterisation and mapping of this mutation, that we named omi (om). Omi is a recessive mutation that leads to degeneration of the incisors, failure of molars to erupt, a grey coat colour, and mild osteopetrosis. We mapped the omi mutation to chromosome 10 between D1OMit214 and D10Mit194. The Ostml gene is a likely candidate gene in this region, and the grey-lethal allele, Ostm $I^{g l}$, and omi mutations fail to complement each other. We show that om/om mice have reduced levels of Ostm1 protein. To date we have not been able to identify the causative mutation. We propose that omi is a novel hypomorphic mutation affecting Ostml expression, potentially in a regulatory element. 


\section{Materials and methods}

Mice

Animal husbandry and experiments were carried out in accordance with UK Home Office regulations. The omi mutation was detected in a line of mice derived from a large-scale mutagenesis screen (Hrabe de Angelis et al. 2000). Male $\mathrm{C} 3 \mathrm{HeB} / \mathrm{FeJ}$ mice were injected with three doses of $80 \mathrm{mg} / \mathrm{kg}$ ENU at weekly intervals, allowed to recover, and mated with uninjected $\mathrm{C} 3 \mathrm{HeB} / \mathrm{FeJ}$ females. F1 offspring were screened for a variety of dominantly inherited defects, including deafness and vestibular (balance) defects. The recessive omi mutation was discovered in a mouse line initially isolated because of its dominantly inherited mild head-bobbing behaviour (ABE9, also known as Bob). We were unable to map the original feature of mild head bobbing to any chromosome and no obvious malformation of the inner ear could be detected (Bosman and Steel, unpublished results). Offspring from the original ENU-mutagenized male were outcrossed to wild-type $\mathrm{C} 3 \mathrm{HeB} / \mathrm{FeJ}$ mice (never exposed to ENU) at least five times, diluting out other mutations resulting from the ENU treatment, before the omi phenotype was discovered. The omi phenotype was not linked to the head bobbing, and mice described here showed no sign of any balance defect. Affected omi mice were provided with a Pico-Vac ${ }^{\circledR}$ soft dietary supplement (LabDiet) which enabled them to survive until adulthood. For all experiments control animals were fed normal diet pellets ad libitum. For all phenotypic analyses the mice were studied on their original $\mathrm{C} 3 \mathrm{HeB} /$ FeJ genetic background and unaffected wild-type or heterozygous littermates were used as controls. Grey-lethal mice were obtained from Prof. T. Jentsch and were genotyped as described previously (Chalhoub et al. 2003).

\section{Genetic mapping}

Om/om animals on a $\mathrm{C} 3 \mathrm{HeB} / \mathrm{FeJ}$ genetic background were outcrossed to $\mathrm{C} 57 \mathrm{BL} / 6 \mathrm{~J}$ mice. +/om offspring were backcrossed to affected (om/om) $\mathrm{C} 3 \mathrm{HeB} / \mathrm{FeJ}$ animals. Backcross mice were collected around weaning time. The mice were killed by cervical dislocation, the teeth were photographed, and tissues were taken for DNA purification. The DNA from 28 backcross offspring exhibiting tooth defects was used in a genome scan to link the tooth defect with a chromosome. A panel of 69 markers spanning the autosomes was used to detect polymorphisms between $\mathrm{C} 3 \mathrm{HeB} / \mathrm{FeJ}$ and $\mathrm{C} 57 \mathrm{BL} / 6 \mathrm{~J}$ mice (Supplementary Table 1). For further fine mapping, another ten polymorphic markers were used (Supplementary Table 2). Single nucleotide polymorphisms (SNPs) between $\mathrm{C} 57 \mathrm{BL} / 6 \mathrm{~J}$ and $\mathrm{C} 3 \mathrm{HeB} / \mathrm{FeJ}$ in the region of interest were identified using a SNP database (http://www.informatics.
jax.org/javawi2/servlet/WIFetch?page=snpQF). Primers spanning the SNPs were designed using Primer3 (http://frodo. wi.mit.edu/) with standard settings (Supplementary Table 2 for primer sequence). PCR products were then sequenced with the forward and reverse primers to detect the SNP using standard techniques.

\section{Phenotypic analysis}

Adult mice were killed by cervical dislocation. For histology, organs of 4-week-old male and female mice ( $n=10$; five om/om and five +/om) were collected and fixed in $10 \%$ neutral buffered formalin. Heads were subsequently decalcified in $10 \%$ EDTA ( $\mathrm{pH}$ 8.0) for 7 days, followed by paraffin embedding. Embryos (E16.5, $n=13$ from heterozygous $\times$ homozygous timed matings) were dissected in ice-cold PBS and decapitated, and the heads were fixed in $10 \%$ neutral buffered formalin for 2 days and processed for paraffin embedding. P7 pups ( $n=10$ from heterozygous $\times$ homozygous matings) were decapitated and the heads were fixed in $10 \%$ neutral buffered formalin and decalcified in $10 \%$ EDTA ( $\mathrm{pH}$ 8.0) for 7 days, followed by paraffin embedding. Serial sections at $7 \mu \mathrm{m}$ were cut and stained with haematoxylin and eosin by standard procedures. To analyse the skeletons, mice (seven male +/om, four male om/om, seven female +/om, and four female om/om) were weighed and anaesthetised by intraperitoneal injection of either Avertin (1.25\%) or $100 \mathrm{mg} /$ $\mathrm{kg}$ ketamine $/ 10 \mathrm{mg} / \mathrm{kg}$ xylazine (dosage of $0.1 \mathrm{ml} / 10 \mathrm{~g}$ mouse weight) at 6-8 and at 12 weeks of age. When ketamine/xylazine was used, the anaesthesia was reversed using a solution of $1 \mathrm{mg} / \mathrm{kg}$ Antisedan $(0.1 \mathrm{ml} / 10 \mathrm{~g}$ mouse weight). Mice were scanned in a MX20 Specimen Radiography System (Faxitron X-Ray Corporation, Lincolnshire, IL, USA) in combination with Faxitron SR v1.2 software. At 12 weeks the density of the tissues was measured using a PIXImus Densitometer in combination with Lunar PIXImus 22.1 software. At 16 weeks of age, all nonfasted mice used for the radiographic skeletal analysis were subjected to a terminal retro-orbital bleed under anaesthesia induced by $100 \mathrm{mg} / \mathrm{kg}$ ketamine/10 mg/ $\mathrm{kg}$ xylazine (dosage of $0.1 \mathrm{ml} / 10 \mathrm{~g}$ mouse weight). A complete blood count and clinical chemistry panel were analysed (http://www.sanger.ac.uk/mouseportal/phenotyp ing/MAHN/plasma-chemistry/). Whole blood was analysed with an automatic haematology analyser which uses spectrophotometry and volume impedance principle to measure white and red blood cell counts, mean corpuscular volume, haemoglobin, erythrocyte indices (haematocrit, mean corpuscular haemoglobin, mean corpuscular haemoglobin concentration, red blood cell distribution width), platelet counts, and mean platelet volume (scilVet Animal Blood Counter, RAB 015 A Ind.E, 22.02.01). Plasma 
chemistry was analysed using an Olympus AU400 for the following parameters: sodium, potassium, chloride, glucose, triglycerides, cholesterol, high-density lipoprotein, low-density lipoprotein (LDL), NEFAC, glycerol, amylase, alanine aminotransferase, alkaline phosphatase, creatine kinase, aspartate aminotransferase, total bilirubin, total protein, albumin, creatinine, urea, calcium, magnesium, iron, phosphate, lactate dehydrogenase, and uric acid.

\section{Western blotting}

Adult mice ( $n=2$ per genotype) were killed by cervical dislocation and adult brains were frozen in liquid nitrogen and stored at $-80{ }^{\circ} \mathrm{C}$ until further use. Brain tissue $(7 \mathrm{ml}$ per $0.379 \mathrm{~g}$ tissue) was lysed by homogenization in an ice-cold Dounce homogenizer in ice-cold DOC buffer [1\% sodium deoxycholate in $50 \mathrm{mM}$ Tris- $\mathrm{HCl}(\mathrm{pH}$ 9.0)] containing Complete protease inhibitors (Roche Applied Science, Indianapolis, IN, USA) according to the manufacturer's instructions. The lysate was incubated in ice for $1 \mathrm{~h}$, spun at $4,000 \mathrm{rpm}$ for $1 \mathrm{~h}$, and then cleared through a 5- $\mu \mathrm{m}$ filter. Protein concentration was determined and similar quantities were loaded on a 4-12\% acrylamide gel (Bio-Rad, Hercules, CA, USA) and blotted. Western blots were blocked for $4 \mathrm{~h}$ at $4{ }^{\circ} \mathrm{C}$ in TBS $+0.1 \%$ Tween-20 (TBST) containing $5 \%$ low-fat milk powder, rinsed in TBST, and then incubated in anti-OSTM1 (catalog No. HPA010851 from Atlas Antibodies, Stockholm, Sweden) diluted 1:2,000 in TBST $+3 \%$ low fat milk overnight at $4{ }^{\circ} \mathrm{C}$. Blots were rinsed and washed $3 \times 10$ min with TBST at room temperature, then incubated with anti-rabbit-HRP (Horse radish peroxidase) diluted 1:50,000 in TBST $+3 \%$ low fat milk overnight at $4{ }^{\circ} \mathrm{C}$. Blots were rinsed and washed $3 \times 10 \mathrm{~min}$ and $2 \times 30 \mathrm{~min}$ in TBST. An ECL Advance kit (Amersham GE Healthcare Life Sciences, Piscataway, NJ, USA) was used to detect HRP activity. Blots were then stripped, blocked, and incubated with anti-PSD95 (catalog No. MA1-046 from Affinity Biosciences, Burwood, VIC, Australia) as described above, except for the use of anti-mouse-HRP as a secondary antibody.

\section{Results}

$O m i$ is a recessive mutation affecting teeth and coat colour

The recessive omi founders were discovered in a mouse line initially discovered because of dominant mild headshaking behaviour (ABE9), although the balance defect was not linked to the tooth defect. In a subset of matings of healthy parents, very small animals were found around the time of weaning, some of which died or had to be culled for welfare reasons. Providing these small mice with a special diet of soft food improved their survival rate. Analysis of these affected mice and normal littermates showed that these small mice lacked most incisors (Fig. 1a, b). In addition, we found that affected mice had a more grey (or less yellow) coat colour than their normal littermates (Fig. 1c, d).

We analysed the breeding records to establish inheritance. Of matings between healthy, unaffected individuals, we obtained either normal offspring only or a mixture of affected and normal offspring (Table 1). In the latter case, we found a ratio of affected:unaffected of approximately $1: 3$, indicating recessive inheritance. We crossed affected animals with normal animals from the colony and found that the offspring could be either all normal or a mixture of affected $(41.4 \%)$ and normal $(58.6 \%)$ (Table 1). Next we crossed an affected male with an affected female and we found that all ten offspring were affected, supporting the recessive inheritance.

When breeding these mice we noticed that some affected $(\mathrm{om} / \mathrm{om})$ mice appeared to have a shortened life span. In crosses where normal, unaffected males were used, these were in good health but culled due to a decrease in breeding performance around 7 months $(n=10$; Table 2). However, seven om/om males were found dead and another 18 had to be culled because of ill health by 6 months (24\%; total $n=104$ ). Similar lethality was found for $\mathrm{om} /$ om females (16\%; 13 of 79 females). Necropsy on these mice did not identify any obvious malformations. However, some nonbreeding om/om males $(n=2)$ survived to at least 1 year of age.

Teeth are formed in om/om mice but are abnormal

To analyse the tooth defect and other skeletal problems over time, we took X rays at 6-8 and 12 weeks of age of + / om and om/om mice (Fig. 2). +lom males and females had normal incisors and molars at 6-8 and 12 weeks (Fig. 2a, data not shown). However, the morphology of incisors and molars was very abnormal in om/om mice (Fig. 2b). The incisors appeared short and the molars were not regularly aligned as in control mice. In addition, it appeared that some molars from om/om mice were still covered by other tissue indicating that these do not erupt (Fig. 2b). Sometimes upper molar 3 was visible within the buccal cavity but appeared damaged.

We sectioned heads of 3-week-old +lom and om/om animals. In normal control +/om mice, all teeth, including molars, were present and erupted (Fig. 3a, data not shown). In om/om mice, we found that incisors had erupted but appeared damaged (data not shown). We also identified molars, but these were still covered with bone and an epithelial cell layer (Fig. 3b). This confirmed that molars failed to erupt in om/om mice. 
Fig. 1 Coat colour and teeth of normal $(+/+$ or $+/ o m)$ and omi (om/om) adult mice. a Normal mice have two upper and two lower incisors, b om/om mice lack most incisors. Any remaining incisors need clipping to prevent overgrowth, c A normal agouti coat colour in mice, $\mathbf{d}$ om/om mice have a less yellow coat
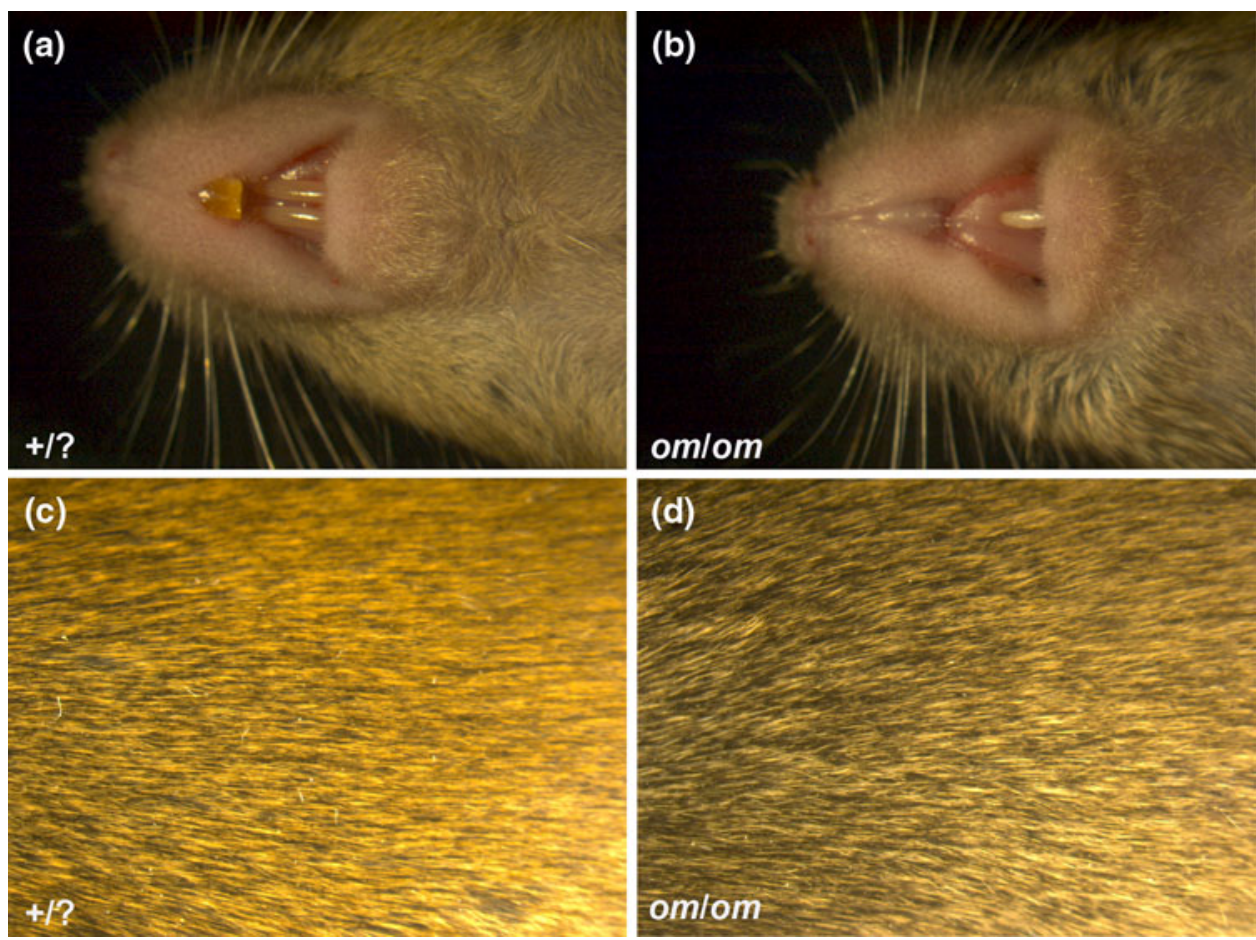

Table 1 The omi mutation is a recessive mutation: numbers of normal and affected mice were analysed to determine mode of inheritance

\begin{tabular}{|c|c|c|c|c|c|c|c|c|c|c|}
\hline \multirow{2}{*}{$\begin{array}{l}\text { Cross predicted } \\
\text { genotypes } \\
\text { Offspring }\end{array}$} & \multicolumn{2}{|c|}{$\begin{array}{l}\text { Unaffected } \times \text { unaffected } \\
+ \text { /om } \times+ \text { /om }\end{array}$} & \multicolumn{2}{|c|}{$\begin{array}{l}\text { Unaffected } \times \text { unaffected } \\
+/ ? \times+/+\end{array}$} & \multicolumn{2}{|c|}{$\begin{array}{l}\text { Affected } \times \text { unaffected } \\
\text { om/om } \times+/ \text { om }\end{array}$} & \multicolumn{2}{|c|}{$\begin{array}{l}\text { Affected } \times \text { unaffected } \\
\text { om/om } \times+/+\end{array}$} & \multicolumn{2}{|c|}{$\begin{array}{l}\text { Affected } \times \text { affected } \\
\text { om/om } \times \text { om/om }\end{array}$} \\
\hline & $n=110$ & $(\%)$ & $n=121$ & $(\%)$ & $n=162$ & $(\%)$ & $n=44$ & $(\%)$ & $n=10$ & $(\%)$ \\
\hline Affected & 25 & 22.7 & 0 & 0 & 67 & 41.4 & 0 & 0 & 10 & 100 \\
\hline Unaffected & 85 & 77.3 & 121 & 100 & 95 & 58.6 & 44 & 100 & 0 & 0 \\
\hline
\end{tabular}

Table 2 om/om mice have a reduced lifespan

\begin{tabular}{|c|c|c|c|c|c|c|c|}
\hline & & \multicolumn{3}{|l|}{$+/ ?$} & \multicolumn{3}{|c|}{ om/om } \\
\hline & & FD & $\mathrm{CS}$ & CXS & FD & $\mathrm{CS}$ & CXS \\
\hline \multirow[t]{3}{*}{ Males } & $n$ & 0 & 0 & 10 & 5 & 4 & 10 \\
\hline & average age (months) & & & 7.2 & 6.0 & 5.6 & 6.7 \\
\hline & SD & & & 1.9 & 1.4 & 1.7 & 1.9 \\
\hline \multirow[t]{3}{*}{ Females } & $n$ & 0 & 0 & 19 & 0 & 0 & 4 \\
\hline & average age (months) & & & 7.8 & & & 6.3 \\
\hline & SD & & & 3.0 & & & 2.8 \\
\hline
\end{tabular}

$F D$ found dead, $C S$ culled sick, $C X S$ culled excess

To determine the onset of the incisor defect, we examined pups from + lom $\times$ om/om matings at several time points. Serial sections of teeth at E16.5 $(n=13)$ showed no obvious abnormalities in any of the embryos (data not shown). We observed 26 offspring from om/om $\times+$ lom matings from P14 until P30-32 and recorded the status of their incisors daily (Table 3). At the end of the time course, 13 mice were scored as affected (om/om) and 13 as normal (+/om) littermates. At P14, five mice, later identified as om/om, had apparently normal incisors. However, six om/ om pups had small or thinner teeth and two mice had missing teeth. At P21, 2 of $13 \mathrm{om} / \mathrm{om}$ mice were scored as having normal incisors, two mice had small or thin teeth, and the remaining nine all had missing teeth. At P30-32, this trend continued and 11 mice had some teeth missing and two had no teeth visible at all. This indicated that the incisors were formed but not maintained.

om/om mice have an abnormal bone morphology and increased bone mass

Analysis of the skeletal structure by X ray showed that $\mathrm{om} /$ om mice had an abnormal skull shape as a result of malformed/eroded teeth. In the maxillary area the bone around the roots of the damaged upper incisors appeared rough. This sclerosis in the maxillary area appeared to get progressively worse, with a denser appearance at the 12-week time point (Fig. 2a-d, data not shown). The zygomatic process of the maxilla was thicker and continued to be 

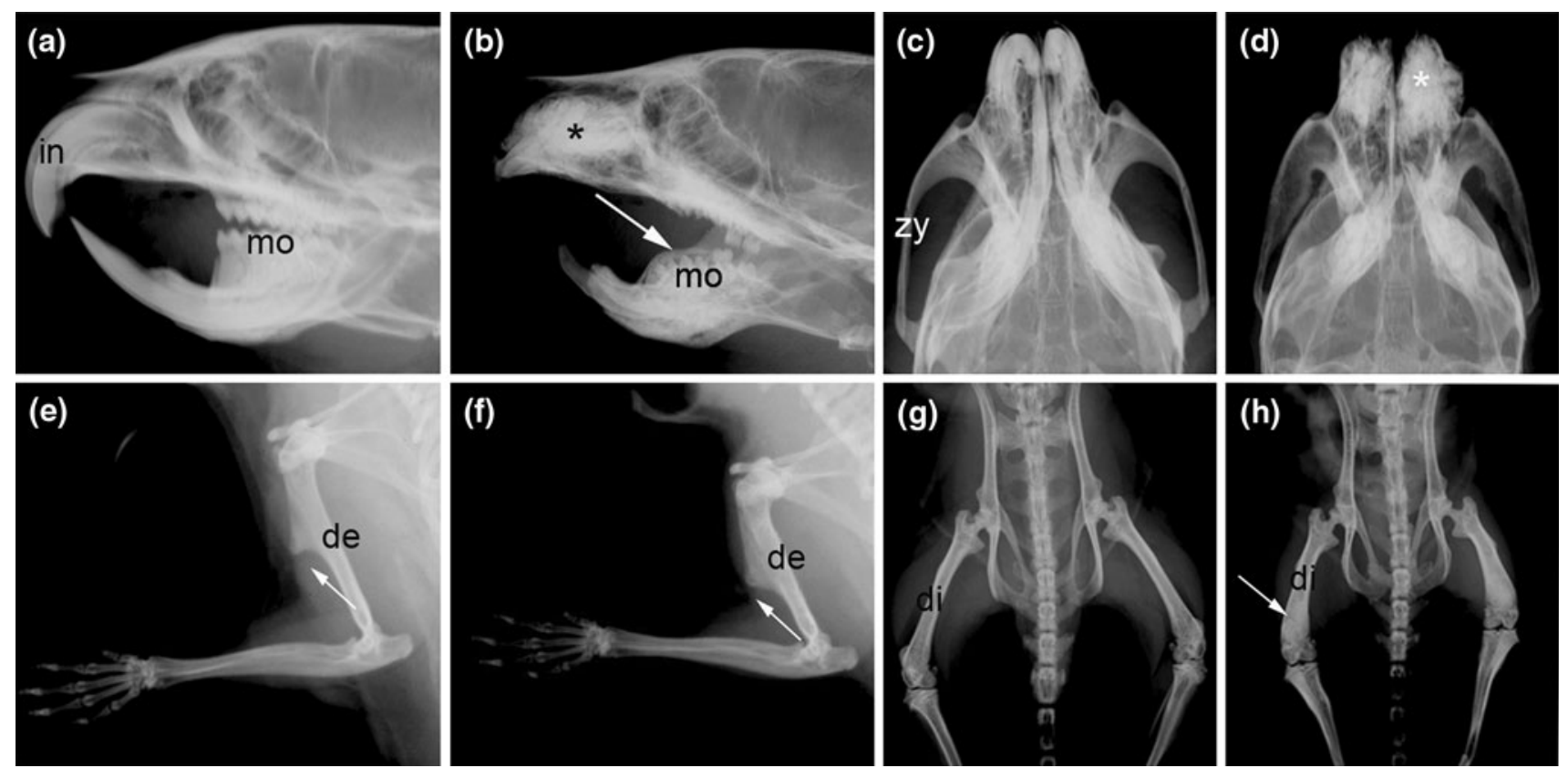

Fig. 2 Analysis of tooth and bone abnormalities in normal $(+/ \mathrm{om})$ and $\mathrm{om} / \mathrm{om}$ adult female mice. a, b Lateral view of the skull of 12-week-old normal (+/om) and omi (om/om) mice. In normal mice, the incisors (in) are clearly visible, and well-defined molars (mo) are visible in the oral cavity. In om/om mice, the incisors are reduced to stumps and misshapen molars appear covered by a tissue layer (arrow). In addition, fibrotic tissue is visible in the maxillary bone (star), c, d Dorsal view of the skull of 12-week-old normal (+/om) and omi (om/om) mice. Compared to normal mice, the zygomatic

thick halfway into the zygomatic bone (Fig. 2c, d). Proximal ribs 1-8 were thickened, especially on the dorsal parts (data not shown). Long bones had a layered appearance and there was an increased density of the deltoid tuberosity of the humeri (Fig. 3e, f) and of the diaphyses of the femurs in females (Fig. 2g, h). In addition, the deltoid process of the humerus had an abnormal morphology (Fig. 3e, f), and femurs were shorter but thicker and had increased density at the distal epiphysis. DEXA scan revealed that om/om mice had a significantly reduced lean and fat mass (Table 4). At 8 weeks, om/om females had a low bone mineral density (BMD), measured over the full body or the femur, when compared to +lom females (Table 4). At 12 weeks, the BMD of om/om females was significantly higher compared to that of +lom controls mice. BMD at the right knee of om/om females was higher at both time points compared to that of + lom females (Table 4). This suggests progressive osteopetrosis in om/om females. The BMD of om/om males was decreased at 8 weeks. At 12 weeks, the BMD of om/om males was similar to that of + lom males. This implies that the progressive osteopetrosis seen in young females is not present in the males at this age. Blood from +lom control and om/om mice was bone (zy) of omi mice is thickened. Fibrotic tissue is visible in the maxillary bone (star), e, f Lateral view of the front leg of 12-week-old normal (+/om) and omi (om/om) mice. The deltoid tuberosity (de) and deltoid process (arrow) are depicted. Note the difference in morphology of the deltoid process between normal and omi mice (arrow), g, h Dorsal view of the hind leg of 12-week-old normal $(+/$ om) and omi (om/om) mice. In omi mice femurs are shorter but thicker and have increased density at the diaphysis (di) and the distal epiphysis (arrow)

analysed. Blood counts were normal (Supplementary Table 3) but clinical chemistry at 16 weeks showed that om/om mice have high alkaline phosphatase levels (males: + lom $=68.24 \mathrm{U} / \mathrm{l}, \quad$ om/om $=96.50 \mathrm{U} / \mathrm{l} ;$ females: $+/$ om $=77.40 \mathrm{U} / \mathrm{l}$, om/om $=130.25 \mathrm{U} / \mathrm{l}$, Supplementary Table 4). Although the level of total alkaline phosphatase (TAP) can be influenced by many factors, TAP is always raised in osteopetrosis patients and mouse models (Sanger et al. 1966; Carolino et al. 1998; Kornak et al. 2001). The higher alkaline phosphatase levels of om/om females may be consistent with the higher BMD seen at 12 weeks. Lower levels of triglycerides, LDL, and haemoglobin in homozygote mice are likely to be an indication of poor nutritional status in om/om mice but could be due to other underlying metabolic problems (Supplementary Table 4).

We analysed haematoxylin and eosin-stained sagittal sections of the heads from 4-week-old +/om and om/om mice for tooth and bone abnormalities. In control mice molars had erupted, but in om/om mice molars were still covered by tissue (Fig. 3a, b). The jaw bones of control mice consisted of spongy bone and compacted bone areas (Fig. 3c, e). In the compacted bone, no blood vessels were seen and the bone had a regular structure (Fig. 3c). In contrast, the areas normally 
Fig. 3 Analysis of tooth and bone abnormalities by histology in 3-week-old normal (+lom) and $\mathrm{om} / \mathrm{om}$ mice. a, b Sections through molars of normal $(+/$ om) and omi (om/om) mice. In normal mice molars ( $m o$ ) have erupted and are located in the buccal cavity, whereas the molars of om/om mice remain in the jaw under several tissue layers, c, d Sections through incisors (in) of normal and om/ om mice. The maxillary bone of normal mice has a compacted and regular structure

(compacted bone, $c b$ ) with no blood vessels. In om/om mice the bone is disorganized (arrowhead) and has many blood vessels penetrating (arrow). Scale bar $100 \mu \mathrm{m}$
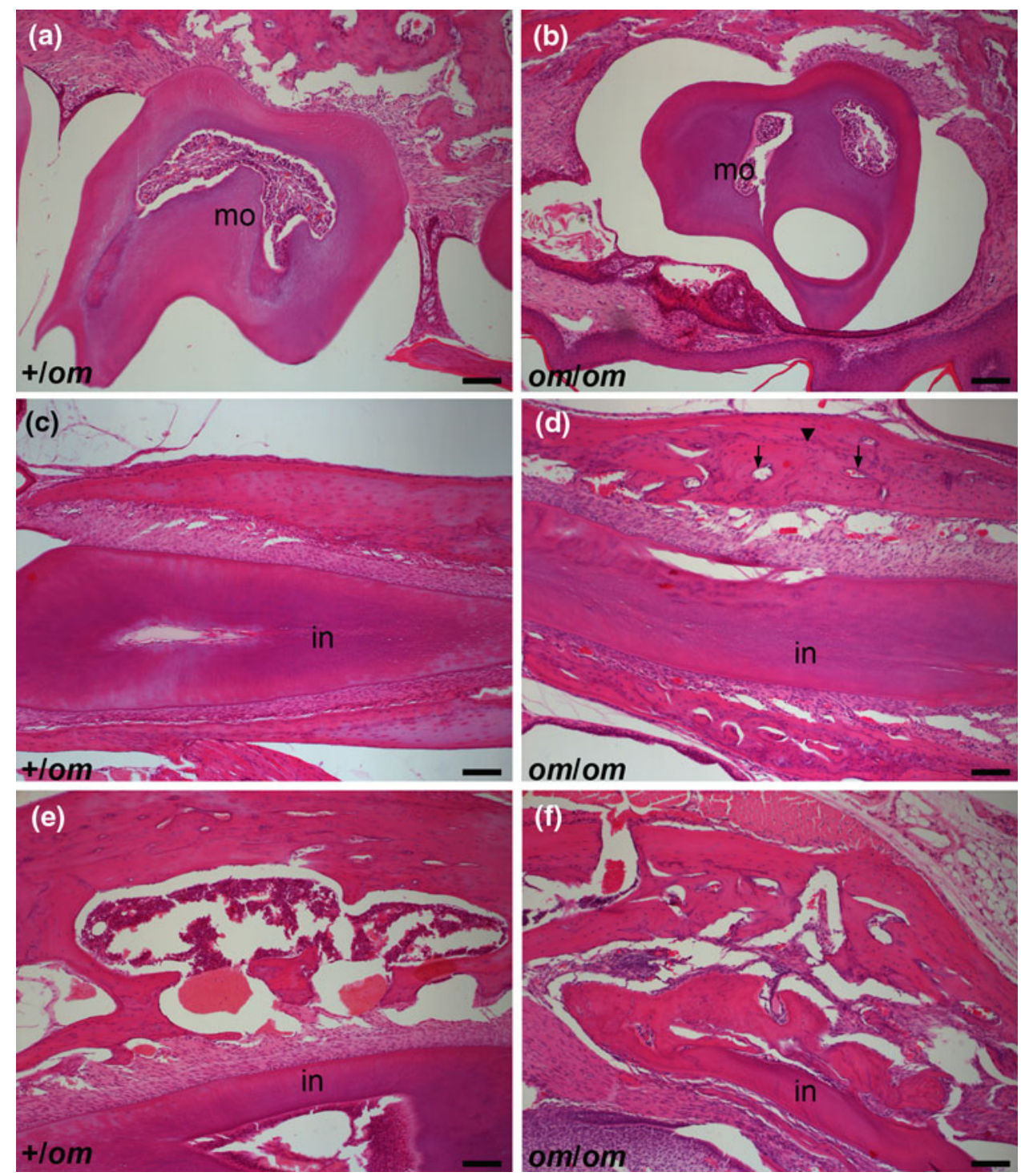

Table 3 Number of control and om/om mice displaying a feature at $\mathrm{P} 14, \mathrm{P} 21$, and P30-32

\begin{tabular}{llrrc}
\hline & Teeth & P14 & P21 & P30-32 \\
\hline +lom $(n=13)$ & Normal size of teeth & 13 & 13 & 13 \\
& Normal number of teeth & 13 & 13 & 13 \\
om/om $(n=13)$ & Normal size of teeth & 5 & 2 & 0 \\
& Small/thin teeth $^{\mathrm{a}}$ & 6 & 2 & 0 \\
& Missing teeth $^{\mathrm{a}}$ & 2 & 9 & 11 \\
& No teeth & 0 & 0 & 2 \\
\hline
\end{tabular}

All control mice had normal teeth at all time points. Incisors erupted in most om/om mice but degenerated after eruption

${ }^{\text {a }}$ Either top or bottom had teeth missing. Of these, six animals had two lower incisors, four animals had one lower incisor, one animal had one top and one lower incisor, and none had only top incisors

formed by compact bone were invaded by blood vessels and had a very irregular structure in om/om mice (Fig. 3d). In addition, the spongy bone appeared disorganised (Fig. 3f).
The omi mutation maps to chromosome 10

To map the omi mutation, we crossed om/om mice with C57BL/6J mice. All offspring $(n=43)$ were normal $(+/$ om) (Table 5). These outcrossed mice were then backcrossed to an affected om/om mouse. A total of 182 backcross mice were collected; $97(53.3 \%)$ had the tooth defect and a grey appearance $(\mathrm{om} / \mathrm{om})$ and $85(46.7 \%)$ were normal in appearance $(+/ o m)$ (Table 5). These crosses indicate an autosomal recessive inheritance. DNA from 28 backcross offspring that had the tooth defect and a grey appearance was used to identify chromosome/trait linkage. Analysis of 69 polymorphic markers (Supplementary Table 1) distributed throughout the autosomes indicated clear linkage of the omi phenotype to chromosome 10 (data not shown). The highest percentage (92\%) of homozygosity for the $\mathrm{C} 3 \mathrm{H}$-type polymorphism was found at marker D10Mit106. To narrow down the region, 
Table 4 Body mass and bone mineral densities (BMD) from control and om/om male and female mice at 8 and 12 weeks of age

\begin{tabular}{|c|c|c|c|c|c|c|}
\hline & & \multirow[t]{2}{*}{ Lean mass (g) } & \multirow[t]{2}{*}{ Fat mass (g) } & \multicolumn{3}{|c|}{$\operatorname{BMD}\left(\mathrm{g} / \mathrm{cm}^{2}\right)$} \\
\hline & & & & Total body & Right knee & Right femur \\
\hline Females & $+\operatorname{lom}(n=7)$ & 19.78 & 5.90 & 0.051 & 0.082 & 0.060 \\
\hline \multirow[t]{2}{*}{8 weeks } & om/om $(n=4)$ & 15.25 & 3.36 & 0.048 & 0.090 & 0.065 \\
\hline & $t$ test & 0.0027 & 0.0370 & 0.069 & 0.030 & 0.117 \\
\hline Males & $+\operatorname{lom}(n=7)$ & 23.95 & 6.74 & 0.053 & 0.088 & 0.066 \\
\hline \multirow[t]{2}{*}{8 weeks } & om/om $(n=4)$ & 18.07 & 3.95 & 0.387 & 0.082 & 0.064 \\
\hline & $t$ test & $1.17 \mathrm{E}-06$ & $1.36 \mathrm{E}-02$ & 0.033 & 0.025 & 0.756 \\
\hline Females & $+\operatorname{lom}(n=7)$ & 22.62 & 9.96 & 0.056 & 0.090 & 0.069 \\
\hline \multirow[t]{2}{*}{12 weeks } & om/om $(n=4)$ & 16.14 & 3.49 & 0.060 & 0.112 & 0.083 \\
\hline & $t$ test & $1.69 \mathrm{E}-05$ & $5.55 \mathrm{E}-04$ & 0.0014 & 0.0002 & 0.0013 \\
\hline Males & $+\operatorname{lom}(n=7)$ & 26.45 & 10.03 & 0.0548 & 0.09 & 0.07 \\
\hline \multirow[t]{2}{*}{12 weeks } & om/om $(n=4)$ & 19.53 & 5.87 & 4.431 & 0.086 & 0.066 \\
\hline & $t$ test & $1.59 \mathrm{E}-06$ & $5.27 \mathrm{E}-05$ & 0.506 & 0.828 & 0.028 \\
\hline
\end{tabular}

we used additional markers on chromosome 10 of the same 28 backcross animals (Supplementary Table 2; data not shown). This narrowed the interval to the region of chromosome 10 between D10Mit214 and D10Mit194, with the highest percentage of homozygosity at DlOMit3 (100\%).

An additional set of $44 \mathrm{om} / \mathrm{om}$ backcross samples was used to confirm the data and to narrow the genomic interval. The haplotypes of the animals defining this critical region are shown in Fig. 3b. One animal was heterozygote for D10Mit3 but homozygote for D10Mit194, narrowing the region to this interval. This corresponds to a $17.6-\mathrm{Mb}$ physical region from 28.8 to $46.5 \mathrm{Mb}$ on chromosome 10 . We then used four SNPs polymorphic between C57 and $\mathrm{C} 3 \mathrm{H}$ that are located in the region between D10Mit3 and D10Mit194 (Fig. 4). The six animals that set the critical interval were used (Fig. 4). Two animals (S7 and S144) were heterozygote for $\mathrm{C} 3 \mathrm{H}$ and $\mathrm{C} 57$ alleles at SNPs rs29330142, rs13480575, and rs13480578. All animals were homozygous for the $\mathrm{C} 3 \mathrm{H}$ allele of SNP rs8244299 at $43.0 \mathrm{Mb}$. Therefore the omi mutation lies in the $12-\mathrm{Mb}$ region between SNP rs13480578 and D10Mit194.

Table 5 Number of affected and normal mice in the out- and backcross confirms recessive inheritance

\begin{tabular}{llrlll}
\hline & \multicolumn{2}{l}{ Outcross } & & \multicolumn{2}{l}{ Backcross } \\
\cline { 2 - 3 } \cline { 5 - 6 } & \multicolumn{2}{l}{ om/om $\times$ C57B16 J) } & & (outcross $\times$ om/om $)$ \\
\hline Offspring & $n=43$ & $(\%)$ & & $n=182$ & $(\%)$ \\
om/om & 0 & 0 & & 97 & 53.3 \\
+ lom & 43 & 100 & & 85 & 46.7 \\
\hline
\end{tabular}

Omi and grey-lethal are noncomplementing mutations

The region on chromosome 10 between SNP rs13480578 and D1OMit194 contains approximately 100 genes. Several genes in the region could lead to a severe phenotype as seen in the om/om mice, but one gene was of particular interest. Ostm 1 mutations have been identified in mouse and human as causing very severe osteopetrosis. Grey-
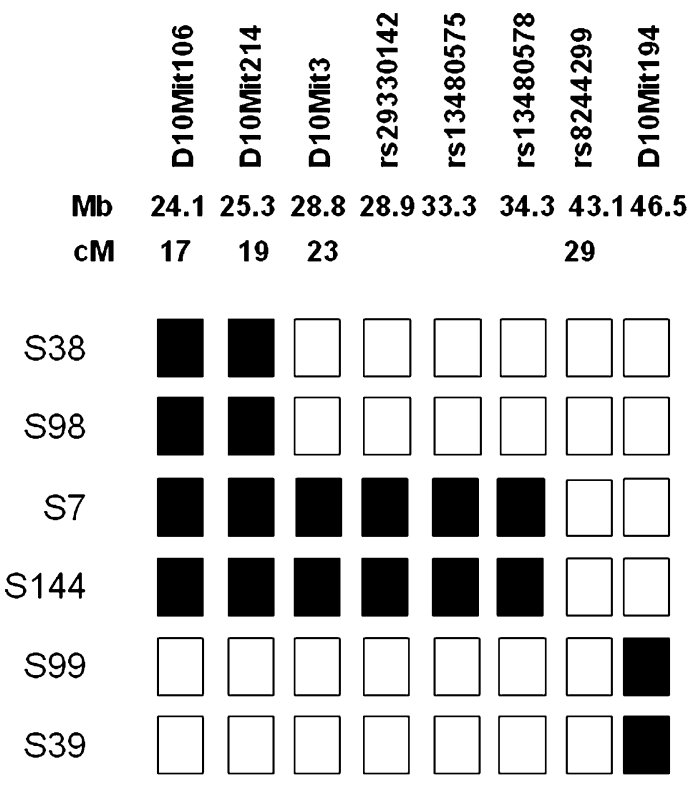

Black $=$ heterozygote, white $=$ homozygote

Fig. 4 Genetic mapping of the omi mutation. A genome-wide association scan using Mit markers located the mutation on chromosome 10. Fine mapping using Mit markers and SNPs polymorphic between $\mathrm{C} 3 \mathrm{H}$ and $\mathrm{C} 57$ mice showed that the mutation lies between rs13480578 and D10Mit194. S(number) sample name, black sample is heterozygous for a marker, white sample is homozygous for a marker, $\mathrm{Mb}$ position of marker on chromosome 10 in megabases 
lethal $(\mathrm{gl})$ mice have a recessive null mutation in Ostm 1 that leads to a grey coat colour and early lethality due to severe osteopetrosis (Chalhoub et al. 2003; Pangrazio et al. 2006). Due to the similarity in phenotype between the grey-lethal and omi phenotypes, we tested for noncomplementation. Offspring of crosses between om/om and $+/ g l$ mice were collected. Of 28 pups, 10 had a grey appearance and lacked incisors at P21 and the remaining pups were all normal (Fig. 5a, b). These ten abnormal pups were confirmed to be heterozygous for the grey-lethal allele by genotyping (and thus $+/ g l,+/ o m$ ). In contrast to $\mathrm{gl} / \mathrm{gl}$ mice, that are small at $\mathrm{P} 21$ and lethal around 3-4 weeks of age, these compound heterozygous mice were viable on a Pico-Vac ${ }^{\circledR}$ soft diet for at least 12 weeks.

om/om mice do not have a mutation in the coding sequence and 500-bp promoter region of Ostm 1 but have reduced Ostm1 protein levels

We sequenced the coding region of $O s t m 1$ in om/om, + lom, and control mice from wild-type $\mathrm{C} 3 \mathrm{HeB} / \mathrm{FeJ}$ colony $(+/+)$ mice. We were unable to detect a mutation within the coding sequence or the $5^{\prime}$ and $3^{\prime}$ UTRs. Work by Meadows et al. (2007) has shown that Ostml expression is regulated by the MIcrophthalmia Transcription Factor (MITF). Analysis of the alignment of human and mouse areas upstream (500 bp) of the transcription start site identified one putative MITF binding site (M box) and three weaker binding sites (E boxes). In addition, Ets and Pu.1 binding sites were identified (Meadows et al. 2007). We sequenced this region for control and om/om mice and did not find any mutation in this promoter region.

Next we analysed Ostm1 protein levels of the brains of $+/ \mathrm{om}$, om/om, and $\mathrm{gl} / \mathrm{gl}$ mice. The OSTM1 antibody recognized several bands ranging from 35 to $90 \mathrm{kDa}$, with the strongest band just above $64 \mathrm{kDa}$. This band was weaker in om/om mice and weakest in $\mathrm{gl} / \mathrm{gl}$ mice compared to the loading control (Figs. 5, 6). This suggests that om/om mice have less Ostm1 protein than normal mice but more than $g l / g l$ mice.

\section{Discussion}

Here we described a novel allele (omi) of Ostml that results in tooth, bone, and coat colour abnormalities. All homozygote mutant (om/om) mice lose incisors in the first month of life and most molars fail to erupt. We have demonstrated that female om/om mice may suffer from progressive osteopetrosis at a young age. Male om/om mice have decreased BMD at 8 weeks of age, but bone mass increases significantly between 8 and 12 weeks of age, even though mice suffer from poor nutritional status (indicated by low triglycerides, LDL, reduced lean and fat mass). In addition, om/om mice have a shortened life span. It is possible that bone mass would increase further with age in om/om males and an osteopetrotic phenotype could underlie the shortened life span, but further detailed analysis of this complex bone phenotype is required.

The omi mutation is likely to have been induced by ENU mutagenesis. A spontaneous mutation rate of $1.1 \times 10^{-8}$ per base per generation was estimated for the mouse (Drake et al. 1998), resulting in an average of 28.6 mutations per genome per generation. In contrast, the mutation rate induced by ENU can be approximately 10,000 times higher than the natural background mutation rate (Salinger and Justice 2008; http://cshprotocols.cshlp. org/content/2008/4/pdb.prot4985.full), for an average of $3.97 \times 10^{7}$ mutations in the first generation. After five generations of outcrossing with unexposed $\mathrm{C} 3 \mathrm{HeB} / \mathrm{FeJ}$, one would expect $93.75 \%$ of the mutations to have been diluted out, leaving around $2.48 \times 10^{5}$ ENU-induced

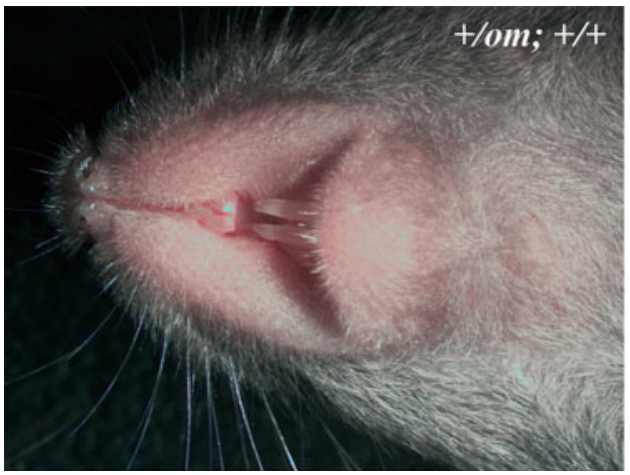

Fig. 5 Genetic complementation. Homozygous omi (om/om) mice were crossed with heterozygous grey-lethal $(+/ g l)$ mice and offspring were analysed for gross morphological defects. a Three-week-old + I om; $+/+$ mice have normal teeth, b A 3-week-old littermate $(+/$

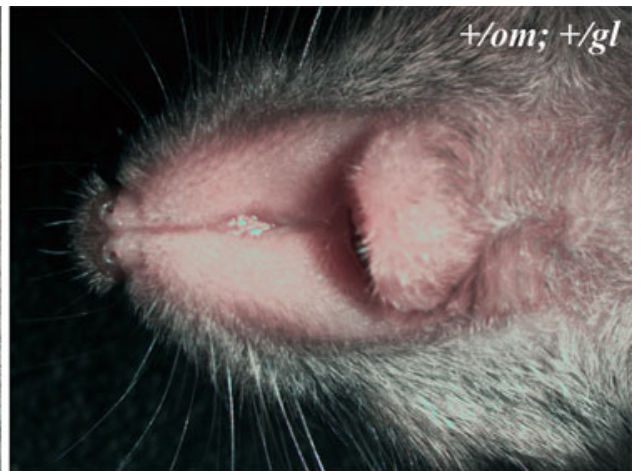

om $;+/ g l)$ has missing incisors and coat colour abnormalities. Unlike $\mathrm{gl} / \mathrm{gl}$ mice, these compound heterozygotes are viable until at least 12 weeks of age 


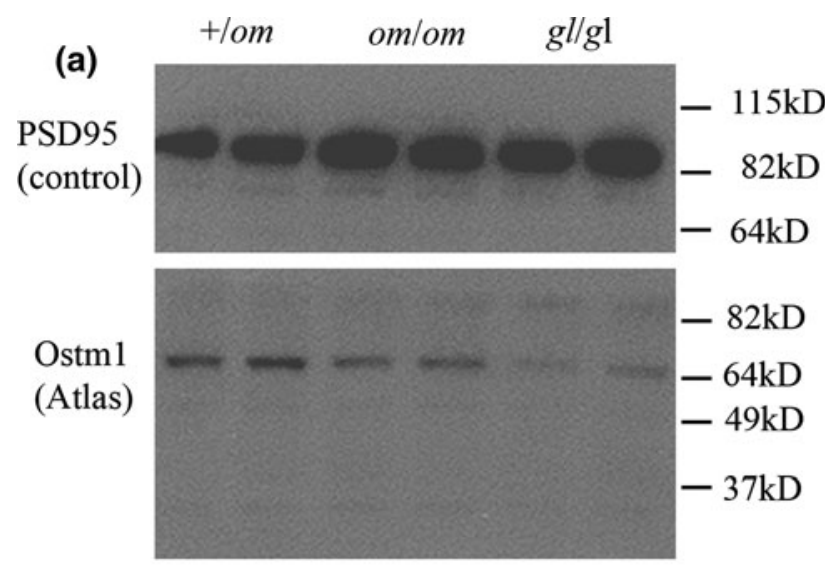

(b)

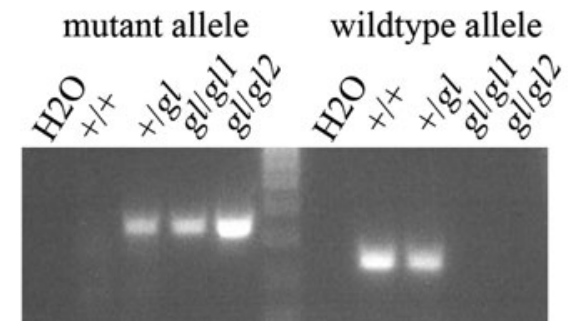

Fig. 6 Ostm 1 protein levels in $+/ o m$, om/om, and $\mathrm{gl} / \mathrm{gl}$ mice analysed by Western blotting. a Brain lysates of 3-week-old +lom,om/om, and $\mathrm{gl} / \mathrm{gl}$ mice were analysed by Western blotting for the Ostm 1 protein. Blots were stripped and incubated with a PSD95 antibody to determine sample loading, b Genotypes of grey-lethal $(\mathrm{gl} / \mathrm{gl})$ samples were verified by PCR analysis

mutations. Therefore, it is likely that the mutation was ENU-induced, but we cannot exclude the possibility that it arose spontaneously.

The phenotype of the om/om mice is similar but not identical to the previously reported grey-lethal mouse. Grey-lethal is a recessive mutation in Ostm1 but has a more severe phenotype than the om/om phenotype across all aspects of the phenotype. Incisors and molars do not erupt in grey-lethal mice. Some teeth do erupt in om/om mice but most are not maintained and are lost just after weaning. In vitro cultures of tooth germs showed that teeth of greylethal mice can develop normally, and the failure to erupt in vivo is due to an absence of bone remodelling (IdaYonemochi and Saku 2002). Grey-lethal mice are not viable and die around weaning time, even when the mice are on an appropriate soft diet, whereas omi mice are viable and fertile on a soft gel diet. The grey coat colour is another phenotype that is more severely affected in grey-lethal mice than in omi mice. The grey-lethal mutation has been bred onto various genetic backgrounds, including $\mathrm{C} 3 \mathrm{H}$ and C57BL/6J. The phenotype of the grey-lethal mouse is less severe on a Mus spretus genetic background, indicating that modifier genes exist (Vacher and Bernard 1999). The omi mutation arose on an inbred $\mathrm{C} 3 \mathrm{HeB} / \mathrm{FeJ}$ genetic background and backcrossing to $\mathrm{C} 57 \mathrm{BL} / 6 \mathrm{~J}$ did not alter the phenotype significantly. Grey-lethal was discovered by Grüneberg (1935) in a stock segregating for $T y r^{c-e}$. It arose as a spontaneous mutation in a mixed genetic background. Based on mapping data, Vacher and Bernard (1999) suggested that the mutation arose on a 129 or related genetic background. The grey-lethal mutation was identified as a genomic deletion of the $5^{\prime}$ region of the gene. The deletion spans $7.5 \mathrm{~kb}$ and includes the promoter, the first exon, and part of the first intron. A 460-bp sequence corresponding to the $3^{\prime}$ UTR of a LINE1 retrotransposon element was inserted at the deletion breakpoints (Chalhoub et al. 2003). RT-PCR showed that this Ostm1 mRNA is not expressed in $g l / g l$ tissues, making it likely that this is a complete null mutation.

One possibility is that the difference in the type of mutation could cause the difference in phenotype. Omi was identified in a mouse line that came from an ENU mutagenesis program. Therefore, it is likely to be a point mutation rather than a retroviral integration as is the greylethal mutation. Omi could be a hypomorphic allele rather than a complete null mutation, which would explain the difference in phenotype. Our data suggest that $\mathrm{om} / \mathrm{om}$ mice have reduced levels of Ostm1 protein, confirming that it is not a null mutation. Our current hypothesis is that the omi mutation could lie in a regulatory element and lead to a reduction in Ostml expression. As enhancer elements have been identified at many kilobases up- or downstream from the transcription start site, further fine mapping of the omi mutation in combination with new sequencing technologies will be required to identify the causative mutation.

Osteopetrosis in humans was described in the early 1900s by Albers-Schönberg, and by the 1940s it was clear that the severity of the phenotype varied greatly. In the most severe forms, deficient bone resorption leads to haematological failure, cranial nerve compression, short stature, and brittle bones. Various inheritance patterns have been described for the different types of osteopetrosis. Autosomal dominant osteopetrosis is variable but usually mild. Various forms of recessive osteopetrosis have been reported, some of which are associated with the most severe phenotypes (including those caused by mutations in the TCIRG1,CLC7, and OSTM1 genes), whereas mutations in other genes (CAII and PLEKHMI) give a milder osteopetrotic phenotype. Recently, long-term survival in infantile malignant autosomal recessive osteopetrosis secondary to homozygous p.Arg526Gln mutation in CLCN7 was described (Kantaputra et al. 2012). Interestingly, the phenotype of omi mice greatly overlaps the description of a case study of recessive mild osteopetrosis (Kahler et al. 1984). As in omi mice, patients presented with oligodontia, striation of the long bones, abnormalities of the zygomatic arch, sclerosis in the skull, and mild anaemia. To date, only four different human OSTM1 mutations have been 
identified, always leading to recessive malignant osteopetrosis. This does not exclude the possibility that other hypomorphic OSTM1 mutations could lead to a mild osteopetrotic phenotype in humans. The recent identification of a similar mutation in CLC7 (Kantaputra et al. 2012) confirms the idea that many more subtle mutations may be identified in the human population. Therapy for osteopetrosis is presently unsatisfactory and much work needs to done to unravel the gene defects and to identify new treatments to improve symptoms. Recent efforts to identify novel genes involved in bone homeostasis by using ENU mutagenesis screening in mice have identified one novel candidate for osteopenia (Barbaric et al. 2008) and one for osteopetrosis (Ochotny et al. 2011). Although omi mice have a mutation that affects a gene already known to be involved in bone homeostasis, it is likely to be hypomorphic making it a suitable model for validating novel therapeutic treatments.

Acknowledgments This study was supported by the Wellcome Trust (grant No. 098051), the MRC, and the EC (BMH4-CT97-2715). The authors thank Heike Brinkmann for collection of backcross mice, Rosalind Lacey for animal care and data collection, Mark Collins for advice on Western blotting and the PSD95 antibody, and Prof. Dr T. Jentsch for the grey-lethal mice. E. A. Bosman thanks W. Skarnes for support and P. Tate for valuable comments.

Open Access This article is distributed under the terms of the Creative Commons Attribution License which permits any use, distribution, and reproduction in any medium, provided the original author(s) and the source are credited.

\section{References}

Barbaric I, Perry MJ, Dear TN, Rodrigues Da Costa A, Salopek D, Marusic A, Hough T, Wells S, Hunter AJ, Cheeseman M, Brown SD (2008) An ENU-induced mutation in the Ankrd11 gene results in an osteopenia-like phenotype in the mouse mutant Yoda. Physiol Genomics 32:311-321

Bosman EA, Penn AC, Ambrose JC, Kettleborough R, Stemple DL, Steel KP (2005) Multiple mutations in mouse Chd7 provide models for CHARGE syndrome. Hum Mol Genet 14:3463-3476

Bosman EA, Quint E, Fuchs H, Hrabe de Angelis M, Steel KP (2009) Catweasel mice: a novel role for Six 1 in sensory patch development and a model for branchio-oto-renal syndrome. Dev Biol 328:285-296

Calvert JA, Dedos SG, Hawker K, Fleming M, Lewis MA, Steel KP (2011) A missense mutation in Fgfrl causes ear and skull defects in hush puppy mice. Mamm Genome 22:290-305

Carolino J, Perez JA, Popa A (1998) Osteopetrosis. Am Fam Physician 57:1293-1296

Chalhoub N, Benachenhou N, Rajapurohitam V, Pata M, Ferron M, Frattini A, Villa A, Vacher J (2003) Grey-lethal mutation induces severe malignant autosomal recessive osteopetrosis in mouse and human. Nat Med 9:399-406

Drake JW, Charlesworth B, Charlesworth D, Crow JF (1998) Rates of spontaneous mutation. Genetics 48:1667-1686

Grüneberg H (1935) A new sub-lethal colour mutation in the house mouse. Proc R Soc Lond (Biol) 118:321-342

Hilton JM, Lewis MA, Grati M, Ingham N, Pearson S, Laskowski RA, Adams DJ, Steel KP (2011) Exome sequencing identifies a missense mutation in Isll associated with low penetrance otitis media in dearisch mice. Genome Biol 12:R90

Hrabe de Angelis MH, Flaswinkel H, Fuchs H, Rathkolb B, Soewarto D, Marschall S, Heffner S, Pargent W, Wuensch K, Jung M, Reis A, Richter T, Alessandrini F, Jakob T, Fuchs E, Kolb H, Kremmer E, Schaeble K, Rollinski B, Roscher A, Peters C, Meitinger T, Strom T, Steckler T, Holsboer F, Klopstock T, Gekeler F, Schindewolf C, Jung T, Avraham K, Behrendt H, Ring J, Zimmer A, Schughart K, Pfeffer K, Wolf E, Balling R (2000) Genome-wide, large-scale production of mutant mice by ENU mutagenesis. Nat Genet 25:444-447

Ida-Yonemochi H, Saku T (2002) No developmental failure of cultured tooth germs from osteopetrotic (op/op) mice. J Oral Pathol Med 31:374-378

Kahler SG, Burns JA, Aylsworth AS (1984) A mild autosomal recessive form of osteopetrosis. Am J Med Genet 17:451-464

Kantaputra PN, Thawanaphong S, Issarangporn W, Klangsinsirikul P, Ohazama A, Sharpe P, Supanchart C (2012) Long-term survival in infantile malignant autosomal recessive osteopetrosis secondary to homozygous p.Arg526Gln mutation in CLCN7. Am J Med Genet A 158:909-916

Kornak U, Kasper D, Bösl MR, Kaiser E, Schweizer M, Schulz A, Friedrich W, Delling G, Jentsch TJ (2001) Loss of the ClC-7 chloride channel leads to osteopetrosis in mice and man. Cell 26:205-215

Meadows NA, Sharma SM, Faulkner GJ, Ostrowski MC, Hume DA, Cassady AI (2007) The expression of Clcn7 and Ostml in osteoclasts is coregulated by microphthalmia transcription factor. J Biol Chem 282:1891-1904

Ochotny N, Flenniken AM, Owen C, Voronov I, Zirngibl RA, Osborne LR, Henderson JE, Adamson SL, Rossant J, Manolson MF, Aubin JE (2011) The V-ATPase a3 subunit mutation R740S is dominant negative and results in osteopetrosis in mice. $\mathrm{J}$ Bone Miner Res 26:1484-1493

Pangrazio A, Poliani PL, Megarbane A, Lefranc G, Lanino E, Di Rocco M, Rucci F, Lucchini F, Ravanini M, Facchetti F, Abinun M, Vezzoni P, Villa A, Frattini A (2006) Mutations in OSTM1 (grey lethal) define a particularly severe form of autosomal recessive osteopetrosis with neural involvement. J Bone Miner Res 21:1098-1105

Salinger AP, Justice MJ (2008) Mouse mutagenesis using $N$-ethyl- $N$ nitrosourea (ENU). CSH Protoc. 2008:pdb.prot4985, doi: 10.1101/pdb.prot4985

Sanger VL, Fredrickson TN, Morrill CC, Burmester BR (1966) Pathogenesis of osteopetrosis in chickens. Am J Vet Res 21:1735-1744

Smits BM, Peters TA, Mul JD, Croes HJ, Fransen JA, Beynon AJ, Guryev V, Plasterk RH, Cuppen E (2005) Identification of a rat model for Usher syndrome type $1 \mathrm{~B}$ by $N$-ethyl- $N$-nitrosourea mutagenesis-driven forward genetics. Genetics 170:1887-1896

Vacher J, Bernard H (1999) Genetic localization and transmission of the mouse osteopetrotic grey-lethal mutation. Mamm Genome 10:239-243 